\title{
Significado da Vivência em Instituição de Longa Permanência
}

Renara Meira Gomes ${ }^{l}$; Jessica de Oliveira Rocha ${ }^{l}$; Maria da Conceição Quirino dos Santos ${ }^{2}$, Zenilda Nogueira Sales ${ }^{3}$, Eliane Fonseca Linhares ${ }^{4}$, Norma Lopes de Magalhães Velasco Bastos ${ }^{5}$

Resumo: Buscando trabalhar com os idosos institucionalizados, o trabalho pretende como objetivo relatar experiências vivenciadas, enfatizando qualidade de vida e os significados por eles atribuídos. Método: tipo qualiquantitativo descritivo, através de entrevista semiestruturada, tabelas, gráficos e um diário de bordo onde o autor deixa suas impressões. Resultados: sendo o asilo a instância encarregada de acolher a face rejeitada do idoso e dentro do possível, reestruturá-lo, oferece aquilo que a sociedade lhe negou. Conclusões: evidentemente que uma carga de dor e sofrimento acompanha aqueles que se encontram na condição de internos, pois ter o asilo como último refúgio significa habitar em um universo paralelo, com um tipo de socialização alternativa, que só em pontos determinados e situações bem específicas interage com o mundo exterior.

Descritores: Idoso institucionalizado; Vivência; Profissional de saúde.

\section{Meaning of Experience in Long-Stay Institution}

\begin{abstract}
In order to work with the institutionalized elderly, the work intends to report experienced experiences, emphasizing the quality of life and the meanings attributed to them. Method: descriptive qualiquantitative type, through semi-structured interview, tables, graphs and a logbook where the author leaves his impressions. Results: Asylum is the body in charge of receiving the rejected face of the elderly and, insofar as possible, restructure it, offers what society denied. Conclusions: evidently a burden of pain and suffering accompanies those who are in the condition of inmates, for to have asylum as the last refuge means to dwell in a parallel universe with a kind of alternative socialization, that only in specific points and very specific situations interacts with the outside world.
\end{abstract}

Keywords: Institutionalized elderly; Experience; Healthcare professional.

\footnotetext{
${ }^{1}$ Graduandas em Enfermagem pela Faculdade de Tecnologia e Ciências de Jequié/Bahia. Endereço: Rua Antônio Orrico, 357, São José/Jequié/BA. E-mail: nara_rhema@hotmail.com; jeuorocha@gmail.com.

${ }^{2}$ Enfermeira, Doutoranda especial em Enfermagem e Saúde, Mestre em Terapia Intensiva, Professora da Faculdade de Tecnologia e Ciências de Jequié/BA. Endereço: Rua Candinha Barreto, 76. Jequiezinho. Jequié/BA, Brasil. E-mail: conceicaoquirino@gmail.com.

${ }^{3}$ Enfermeira, Doutora (Pós - doutora), Professora Plena departamento de Saúde II, Universidade Estadual do Sudoeste da Bahia/UESB. Endereço: Avenida José Moreira Sobrinho, SNº. Jequié/BA, Brasil. E-mail: zenysalles@ gmail.com.

${ }^{4}$ Enfermeira, Doutora, Professora Plena departamento de Saúde II da Universidade Estadual do Sudoeste da Bahia/UESB. Endereço: Rua Padre Altino Freire, 659. Centro. Jequié/BA, Brasil.E-mail: e-linhares@ bol.com.br.

${ }^{5}$ Enfermeira, Mestre em Terapia Intensiva, Professora Plena departamento de Saúde II, Universidade Estadual do Sudoeste da Bahia/UESB. Endereço: Avenida José Moreira Sobrinho, SNo. Jequié/BA, Brasil. E-mail: normademagalhaes@ gmail.com. Autor correspondente: Renara Meira Gomes. Rua Isaías Rêgo, 30, Centro. Dário Meira/BA. E-mail: nara_rhema@hotmail.com
} 


\section{Introdução}

$\mathrm{Na}$ atual conjectura social o processo de envelhecer analisado pelo autor através do presente trabalho busca expor a interação que ocorre entre os idosos em locais totalmente diversificados do seu cotidiano, ou seja, instituições de longa permanência destinadas a receber essas pessoas que de acordo a sociedade são vistas como improdutivas.

Buscando aprofundar o conhecimento sobre o tema proposto, percebem-se alguns estudiosos demonstram através de seus estudos uma grande preocupação com o envelhecimento populacional, fenômeno que ocorre principalmente em países em desenvolvimento, no contexto de grande desigualdade social (ROSA, 2003). Nestes países, o aumento de idosos vem acontecendo de forma acelerada; sendo estimado para 2025 que entre os dez países com maior número de idosos, cinco serão em desenvolvimento (WORLD, 2005).

Segundo as projeções estatísticas da Organização Mundial da Saúde (OMS) O período de 1975 a 2025 é considerado a era do envelhecimento - a população de idosos no País crescerá 16 vezes - alocando o Brasil em termos absolutos como a sexta população de idosos do mundo, ou seja, mais de 32 milhões de pessoas com 60 anos ou superior a esse número. Juntamente a essa transição demográfica, ocorreu uma importante transformação do perfil das doenças na população, cujas enfermidades próprias do envelhecimento, que costumam ser crônicas e múltiplas, absorveram maior expressão no conjunto da sociedade (WORLD, 2005).

Nessa categorização de sexta posição, e cuja faixa central está entre oitenta anos ou mais de idade, o país requer um sistema de saúde mais estruturado para atender a essa demanda crescente, bem como medidas urgentes por parte do governo e da sociedade em geral (CARVALHO, 2006).

Nesse contexto, o idoso institucionalizado constitui, quase sempre, um grupo de indivíduos privado de seus projetos, encontra afastado da família, residência, dos amigos, das relações interpessoais as quais sua história de vida foi construída. Associa-se com facilidade a essa exclusão social as marcas e sequelas das doenças crônicas não transmissíveis, as quais são os motivos principais de sua internação inclusive nas Instituições de Longa Permanência (ILP).

Nesse sentido, com o envelhecimento e exclusão do convívio familiar se concretizam novas experiências entre os idosos que interagem com outros, com maturidades semelhantes, perdas e incapacidades que se caracterizam pelos aspectos da senescência e a senilidade. 
O processo de envelhecer está representado nos dois aspectos supracitados. A senescência se confirma como fase normal da vida, na qual o individuo envelhece de forma gradativa e natural sem com isto se manifestar sinais sugestivos de doenças ou distúrbios de conduta como amnesia ou perda de controle de si mesmo, enquanto que senilidade diz respeito a demência, posto que o idoso perde a capacidade de memorização, apresenta déficit de atenção, desorientação, fala sem nexo, ficando o mesmo limitado ao leito, com incontinências urinárias e intestinais. Pode-se dizer que o processo do envelhecimento humano ocorre no nível biopsicossocial (ROSA, 1993).

Com base neste enunciado, a Política Nacional do Idoso (PNI) regulamentada pela Lei 8.842/94 tendo como finalidade assegurar os direitos sociais do idoso, criando condições para promover sua autonomia, integração e participação efetiva na sociedade. A partir dessa explanação, traz responsabilidades partilhadas pelo Estado, família, sociedade civil, ministério público, órgãos públicos e instituições sociais. Com isso, retoma o estabelecido na Constituição Federal dizendo que compete à família, à sociedade e ao Estado o dever de certificar ao idoso todos os direitos de cidadania, garantindo sua participação na comunidade, defendendo sua dignidade, bem-estar e o direito à vida (BRASIL, 2008).

Nesse argumento, ser velho não é um sinônimo de doença ou incapacidade, pode-se atingir e desfrutar da velhice de forma saudável, com propriedade e descanso. Existem varias mudanças no processo de envelhecer que são naturais, que chamamos de modificações biológicas e/ou psicossociais como aparecimentos de rugas e cabelos brancos, esquecimentos, doenças do coração, osteoporose, dentre outras. Sendo o envelhecimento um processo natural aos quais os indivíduos percorrem no decorrer de suas existências, pode advier de maneira saudável e bem sucedida. Uma vez que estimuladas e motivadas às atividades cotidianas (mobilidade e interação), os idosos tendem manter e prolongar a independência e autonomia.

Essa temática emergiu durante as atividades desenvolvidas no abrigo de idosos do município denominado Fundação Leur Britto, no estado da Bahia. No primeiro contato com os idosos que residiam no referido abrigo, foi possível observar como eles expressavam seus sentimentos de forma diferenciados, muitas vezes agressivos, outras vezes apáticos, como se estivessem infelizes, ou insatisfeitos por estarem naquela instituição.

Partindo desse pressuposto o presente estudo teve como questão compreender como ocorre o processo do envelhecimento do idoso institucionalizado? Para responde a nossa 
inquietação objetivou-se relatar experiências vivenciadas pelos idosos, enfatizando a qualidade de vida e os significados por eles atribuídos no meio institucionalizado.

Esse estudo tem como característica desvelar a importância das ações de cuidado, afetividade, apoio emocional, solidariedade e interesse em geral para com os idosos institucionalizados, mostrando ainda sua vivência em uma instituição de longa permanência. Ademais proporcionar conhecimentos aos estudiosos e futuros profissionais da área de saúde por meio da contribuição científica.

\section{Método}

Trata-se de um estudo descritivo com abordagem qualiquantitativa desenvolvido em um município no interior do estado da Bahia, Brasil, desenvolvido no período de 15 a 25 de setembro de 2014.

No desvelar de suas nuances, a pesquisa qualitativa objeta as questões muito particulares. Ela se preocupa, nas ciências sociais, com nível superior de uma realidade que não pode ser quantificado, ou seja, ela trabalha com o universo de significados, motivos, aspiração, crenças, valores e atitudes, o que sinteticamente falando, correspondem a um espaço mais profundo das relações dos processos e dos fenômenos que não podem ser restringidos à operacionalização de variáveis [...] (MINAYO, 2011).

Contrapondo a isso, o método quantitativo se caracteriza pelo emprego da quantificação, tanto nas modalidades de coleta de informações, quanto no tratamento dessas através de técnicas estatísticas, desde as mais simples até as mais complexas (BARDIN, 2012).

Sendo assim, compreende-se que a abordagem quantitativa e a qualitativa são métodos diferentes por suas sistemáticas, e, principalmente, pela forma de abordagem do problema que está sendo objeto de estudo, se tornando necessário, adequar ao tipo de pesquisa que se deseja desenvolver. Os dados quantitativos serão apresentados através de tabelas e gráficos analisados quantitativamente de acordo com as respectivas frequências apresentadas. Enquanto que os dados qualitativos foram ser analisados de acordo com a análise temática do conteúdo (BARDIN, 2012).

Este estudo teve como cenário uma Instituição de longa permanência localizada em uma cidade do interior da Bahia, administrada por freiras de uma Congregação denominada Servas 
da Sagrada Família. A instituição conta com uma população total de 54 idosos, porém foi selecionada uma amostra com 16 participantes após percorrer o universo supracitado e constatar que cerca de $60 \%$ dos internos sofrem por algum tipo de sanidade mental ocasionada pelo envelhecimento após processo de enclausulamento social, apresentando desmemorização temporária ou permanente, descontrole dos esfíncteres, desorientação seguida de respostas sem nexo.

Nesse sentido, a seleção da amostra correspondente a 75\% do total de 22 idosos com sanidade mental em bom estado de saúde. Essa percentagem se justifica por confiar que o quantitativo de 16 participantes corresponde aos idosos que aceitaram responder a pesquisa espontaneamente, sendo afirmado através da assinatura no termo de consentimento livre e esclarecido. Foram informados pelo pesquisador que poderiam a qualquer momento desistir de suas participações sem gerar dano algum para ambas as partes. Foram utilizados como critério de inclusão os idosos com capacidade de responder ao questionário durante a entrevista e aceitar participar do estudo, podendo os mesmo abandonar a qualquer tempo sem dano algum para a sua saúde.

Como instrumento de coleta de dados foi utilizado uma entrevista semiestruturada, contendo perguntas abertas e apenas uma fechada, com vistas a mostrar a convivência de cada idoso através do conhecimento das atividades básicas desenvolvidas no meio institucionalizado, e, a realidade humana de cada participante, vale salientar que em caso de idosos que não sabiam escrever suas entrevistas foram transcritas pelo redator/autor, ao tempo em que foram lidas em sua íntegra para os participantes em tempo real, no intuito de evitar qualquer desconforto por parte dos mesmos.

Respeitando suas crenças e valores enquanto indivíduos, as entrevistas foram transcritas em suas formas originais de falas, por entender que para fazer parte das representações sociais aqui exemplificadas, torna-se necessário manter uma comunicação coloquial no nível do entrevistado, visto que dessa forma, o participante possa se sentir aceito, compreendido e respeitado no universo de suas memórias (HALBWACHS, 2004).

Nessa linha, a história oral está centrada na memória humana e sua capacidade de rememorar o passado através das vivências coletivas, constituindo elemento essencial na formação de suas identidades, sendo destacadas através das percepções de si e dos outros ao seu redo (HALBWACHS, 2004). 
Após a disposição das informações, obtidas através do roteiro de entrevista, buscou-se por meio da leitura crítica e analítica, interpretar os dados coletados, considerando a importância de uma leitura atenciosa das informações, a fim de obter significados que muitas vezes não estão visivelmente aparentes (BARDIN, 2012).

Vários são os métodos para se utilizar na análise e interpretação dos dados obtidos em diversos tipos de pesquisas. A expressão mais comumente usada para representar os dados de uma pesquisa qualitativa é a analise de conteúdo. Posto que a análise de conteúdo é uma técnica de investigação que tem por finalidade a descrição objetiva, sistemática e quantitativa do conteúdo manifestado pela comunicação (RICHARDSON, 1999).

Obedecendo aos preceitos éticos e legais da pesquisa que envolve seres humanos no Brasil, o projeto de pesquisa foi devidamente encaminhado para a Plataforma Brasil sob o título maior do projeto guarda-chuva: Universo da Atenção a Rede Básica na Saúde do Idoso, Saúde da Mulher, do Homem e da Criança, com envio de todos dos documentos solicitados pela mesma, estando todos devidamente preenchidos e assinados pelos participantes da pesquisa, incluindo Carta de Anuência assinada pelo responsável da instituição escolhida. Após análise do Comitê de Ética e Pesquisa da Universidade Estadual do Sudoeste da Bahia/UESB, o trabalho foi aceito para dar continuidade estando sob o registro da CAAE número 25224913.7.0000.5032, parecer número 484.644. A coleta de dados ocorreu após a assinatura do Termo de Consentimento Livre e Esclarecido (TCLE) pelos idosos que informados sobre os objetivos e riscos da pesquisa, concordaram em participar do estudo.

\section{Resultados e Discussão}

Para a análise dos dados foi utilizado uma tabela contendo informações sociodemográficas de cada participante de forma respectiva. Para identificação dos participantes foi utilizado a letra $\mathrm{E}$ acompanhada do número da entrevista correspondente.

De acordo com os dados que foram tabelados percebe-se que os idosos conduzidos à instituição de longa permanência são pessoas aposentadas, maior parte deles declarados solteiros em seu estado civil. Ressaltamos que tais informações foram obtivas no livro de registro da referida instituição, na qual ainda registra os direitos e deveres iguais para todos os idosos que ali residem. Do total, 15 dos entrevistados se declararam católicos e apenas um 
participante se diz protestante. Em relação ao item profissão exercida anteriormente à aposentadoria, $75 \%$ dos idosos não eram trabalhadores assalariados, apenas exerciam atividades afins sem constatação de vínculo empregatício pelo regime CLT ou concurso público; $12,5 \%$ exerciam a função de lavradores, e 6, 25\% eram serralheiros e, na mesma proporção agricultores.

Desse modo, compreende-se que $100 \%$ dos idosos residentes na instituição de longa permanência, são pessoas carentes excluídos do seu grupo de pertencimento, visto que perderam o vínculo afetivo com seus familiares. Dos entrevistados $87,5 \%$ são solteiros e alguns nunca tiveram relacionamentos duradouros, desse percentual apenas $12,75 \%$ tiveram filhos. De acordo a literatura descrita abaixo é cada vez menor o número de pessoas em uma família, com isso o homem busca cada vez mais a necessidade de ficar sozinho.

A esfinge da época é, então, o de compatibilizar a individualidade e a reciprocidade dos familiares. As pessoas querem aprender, ao mesmo tempo, a serem sós e a 'serem juntas. Para isso, tem que enfrentar a questão de que, ao se abrir espaço para a individualidade, necessariamente se insinua uma ou outra concepção das relações familiares" (Carvalho, 2003).

O aumento da esperança de vida veio provocar um contínuo e progressivo envelhecimento demográfico. As consequências do envelhecimento da população fazem-se sentir não só nas áreas social e político-econômica, mas também na área da saúde e nos comportamentos familiares.

As várias teorias e perspectivas que procuram explicar o envelhecimento, as condições de vida da pessoa idosa e os contextos envolventes são retratados, ao longo do nosso estudo. Sublinha-se a importância da família para o bem-estar e equilíbrio do idoso e referem-se às diferentes formas de suporte social a que o idoso tem acesso.

Em continuação com a apresentação dos resultados, expostos a seguir o gráfico 1 onde foram expostos os dados obtidos após questionamentos relacionados às atividades cotidianas básicas desenvolvida por cada idoso dentro da instituição de longa permanência.

Analisando estatisticamente o gráfico 1 referente as atividades básicas da vida diária foi possivel perceber que $81,25 \%$ dos idosos participantes afirmaram que não necessita de auxilio para o banho e vestir-se, 87,5 garantiram que conseguem se alimentar sozinho, assim como usar o banheiro, concomitante a isso $75 \%$ relataram que conseguem caminhar sem ajuda e por fim apenas $12,5 \%$ conseguem subir escadas sem auxilio. 
Alguns idosos mesmo sendo fisicamente frágeis eles apresentam capacidade mental ativa e força em espirito, onde uma rotina pré-estabelecida proporciona uma sensação de segurança, sabendo que uma determinada atividade tem hora e lugar determinados e planejados para acontecerem. Sendo assim, como vimos na tabela acima eles não perdem a capacidade de desenvolver as atividades básicas da vida diária, sendo refletidos através da perda significativa nas alterações músculos esqueléticas, no qual o idoso tem uma perda da forma muscular, resistência e agilidade ${ }^{14}$.

Com base na analise de conteúdo dos sujeitos investigados o significado da vivência em instituição de longa permanência deu origem a cinco categorias com suas respectivas subcategorias; Ingresso do idoso no asilo; Respeito a vontade do idoso; Grau de satisfação do idoso relacionado a ILP; Sentimentos relacionados á convivência no seio familiar; Convívio institucional e relacionamento interpessoal

\section{Categoria 1: Ingresso do idoso no asilo}

Revisando a temática percebe-se que os idosos se sentem isolados e abandonados no seio familiar, tendo apoio social apenas no seu ingresso na instituição.

Existe uma cultura de rejeição social, relacionada a ILPI e seu simbolismo, ao passo que tornar-se imprescindível a sua existência para os idosos sem condições de tocar sua vida autonomamente (BESSA, 2008).

De acordo com o pensamento literário acima, segue as respostas descritas pelos os entrevistados:

$\boldsymbol{E} 1$ [...]porque eu sai de noite de casa... ai eu vim na caçamba mais o chofer[...] $\boldsymbol{E} 2$ [...] eu vim só[...] $\boldsymbol{E}$ 3 [...] meu filho... ele me trouxe para aqui[...] $\boldsymbol{E} \mathbf{4}$ [...] foi minha cunhada que arrumou, primeiro foi meu irmão[...] $\boldsymbol{E} 5$ [...] minha irmã pensou que eu não podia ficar em casa só, ai internou aqui[...] $\boldsymbol{E} 6$ [...]minha sobrinha me trouxe, eu também escolhi vim pra cá[...] $\boldsymbol{E} 7[\ldots]$ me trouxeram [...] $\boldsymbol{E} 8[. .$.$] foi$ meu sobrinho[...] $\boldsymbol{E} 9$ [...] eu vim com o juizado de menor[...] $\boldsymbol{E} 10$ [...] vim porque quis[...] $\boldsymbol{E} 11$ [...]vim só com minha irmã [...] $\boldsymbol{E} 12$ [,,] vim porque quis, eu que pedia[...] $\boldsymbol{E} 13$ [...]dai doutor Eduardo me trouxe pra fundação[...] $\boldsymbol{E} \mathbf{1 4}$ [...]minha irmã que me trouxe... eu que quis vim[...] $\boldsymbol{E} \mathbf{1 5}$ [...] ]eu que quis vim... eu vi que não dava pra ficar[...] $\boldsymbol{E} 16$ [...]vim trazida pela assistência[...] 


\section{Categoria 2: Respeito a vontade do idoso}

Analisando a colocação quanto ao fato de que o convívio no ambiente institucional é retratado como interrupção abrupta da vida do idoso, essa separação repentina às vezes não é notada, e em continuação da afirmação BESSA, (2008), também analisa essa segregação diz que esse ato invade o meio moral de cada um.

Dessa forma, podemos subdividir a categoria três em duas subcategorias:

Subcategoria 1: houve respeito

$\boldsymbol{E} 3[$ [...] ai eu falava quero, ai eu vim[...].E 6 [...] sim, eu que escolhi vim[...].E 10 [...] sim, vim por vontade própria[...].E 11 [...] sim, por minha própria vontade[...].E 12 [...] eu pedia para me trazer, foi por minha vontade[...].E 14 [...]foi da minha vontade[...].E 15 [...] sim, eu quis vim[...]

Percebe-se que cerca de cinquenta por cento dos idosos entrevistados relatam que as determinações relacionadas aos seus desejos ou vontades no que diz respeito às suas vidas futuras nem sempre são respeitadas, devido aos seus estados cada vez mais dependentes seus familiares se sentem no direito de não só intervir como provocar mudanças nas escolhas feitas por cada um. Isso está intrinsicamente refletido em suas respostas.

Subcategoria 2: Não houve respeito

$\boldsymbol{E} 1$ [...]Ismael conformô com o homem da caçamba e me trouxe[...] $\boldsymbol{E} 2$ [...] me colocou pra dentro e eu não sai mais[...] $\boldsymbol{E} 4$ [...] ou querendo ou não tenho que vim[...] $\boldsymbol{E} 5$ [...]não... veio por que me trouxeram[...] $\boldsymbol{E} 7$ [...] ]eu não lembro assim não[...] $\boldsymbol{E} 8$ [...]Queria que tivesse outro lugar[...] $\boldsymbol{E} \boldsymbol{9}$ [...] Não] $\boldsymbol{E} 13$ [...] Não... ai a mulher me colocou no carro e me trouxe[...] $\boldsymbol{E} \mathbf{1 6}[. .$.$] Foi a precisão de ganhar$ dinheiro[...]

De acordo com a vida de cada família contemporânea atualmente vivenciada na realidade, o espaço para os idosos no seio familiar torna-se cada vez mais restrito, seus filhos a medida que se tornam pais consequentemente não possuem mais tempo para cuidar do idoso familiar, devido a isso busca soluções adversas sem questionar se essas fazem parte ou não da vontade do ser que será conduzido para uma instituição de longa permanência. 


\section{Categoria 3 : Grau de satisfação do idoso relacionado a ILPI}

Sabendo que a ILPI atua como facilitadora do processo de envelhecimento, ao promover atividades que tragam satisfação pessoal e estímulo aos residentes, é necessária envolver os próprios idosos no planejamento de atividades que lhes agradam e atendem aos seus objetivos individuais promovendo harmonia e a segregação social, além de promover a qualidade de vida e as oportunidades de crescimento pessoal de seus residentes (TOMASINI, 2007).

Sendo assim percebe-se que as respostas obtidas comprovam a afirmação dos autores supracitados TOMASINI, (2007), como podemos constatar com as respostas a seguir:

$\boldsymbol{E} 1[\ldots]$ serve sempre $[\ldots] \boldsymbol{E} \mathbf{2}[\ldots]$ gosto deles tudo [...] $\boldsymbol{E} \mathbf{3}[\ldots]$ é bom [...] $\boldsymbol{E} \mathbf{4}[\ldots]$ é um lugar alegre $[\ldots] \boldsymbol{E} 5[\ldots]$ gosto, é bom [...] $\boldsymbol{E} \boldsymbol{6}[\ldots]$ é bom, tá até bem [...] $\boldsymbol{E} 7[\ldots]$ é razoável [...] $\boldsymbol{E} \boldsymbol{8}[\ldots]$ só esperando a vontade de Deus [...] $\boldsymbol{E} 9$ [...] gosto demais disso aqui [...] $\boldsymbol{E} 10$ [...] tô doido pra ir embora [...] $\boldsymbol{E} 11$ [...] o pessoal são todos bom para mim [...] $\mathbf{E} 12$ [...] gosto de morar aqui [...] E 13 [...] mas gostaria de ir pra casa [...] $\boldsymbol{E} 14$ [...] é bom demais [...] $\boldsymbol{E} 15$ [...] eu gosto até [...] E 16 [...] é bom [...]

Subcategoria 1: houve respeito

$\boldsymbol{E} 3[\ldots]$ ai eu falava quero, ai eu vim[...].E 6 [...] sim, eu que escolhi vim [...].E 10 [...] sim, vim por vontade própria[...].E 11 [...] sim, por minha própria vontade[...].E 12 [...] eu pedia para me trazer, foi por minha vontade[...].E 14 [...]foi da minha vontade[...].E 15 [...] sim, eu quis vim[...]

Percebe-se que cerca de cinquenta por cento dos idosos entrevistados relatam que as determinações relacionadas aos seus desejos ou vontades no que diz respeito às suas vidas futuras nem sempre são respeitadas, devido aos seus estados cada vez mais dependentes seus familiares se sentem no direito de não só intervir como provocar mudanças nas escolhas feitas por cada um. Isso está intrinsicamente refletido em suas respostas.

Subcategoria 2: Não houve respeito

$\boldsymbol{E} 1$ [...]Ismael conformô com o homem da caçamba e me trouxe[...] $\boldsymbol{E} 2$ [...] não sai mais[...] $\boldsymbol{E} 4$ [...] ou querendo ou não tenho que vim[...] $\boldsymbol{E} 5$ [...]não... veio por que me trouxeram[...] $\boldsymbol{E} 7$ [...] ]eu não lembro assim não[...] $\boldsymbol{E} 8$ [...]Queria que tivesse outro lugar[...] $\boldsymbol{E} \boldsymbol{9}[. .$. Não] $\boldsymbol{E} 13[\ldots]$ Não... ai a mulher me colocou no carro e me trouxe[...] $\boldsymbol{E} \mathbf{1 6}[. .$.$] Foi a precisão de ganhar$ dinheiro[...] 
De acordo com a vida de cada família contemporânea atualmente vivenciada na realidade, o espaço para os idosos no seio familiar torna-se cada vez mais restrito, seus filhos a medida que se tornam pais consequentemente não possuem mais tempo para cuidar do idoso familiar, devido a isso busca soluções adversas sem questionar se essas fazem parte ou não da vontade do ser que será deportado para uma instituição de longa permanência.

\section{Categoria 4: Sentimentos relacionados à convivência do seio familiar}

Souza $^{16}$ explica que o aumento do sofrimento na instituição juntamente com o isolamento do idoso relacionado a convivência com os outros internos está diretamente ligados ao afastamento do calor humano familiar.

Nesse sentido a categoria quatro nos leva a refletir sobre os sentimentos dos idosos e nos instiga a subdividi-la em duas sub categorias, sendo elas:

Subcategoria 1: Aceitação da atual situação

$\boldsymbol{E} 1$ [...]Lembro de uma porção de coisas[...] $\boldsymbol{E} 2$ [...]Daí de fora eu sinto saudade[...] $\boldsymbol{E} 3$ [...]Sempre sinto, demais[...] $\boldsymbol{E} 6$ [...] Sim minha fia, eu tenho[...] $\boldsymbol{E} 7$ [...] Sinto filha[...] $\boldsymbol{E} 8$ [...]lá fora? As vezes[...] $\boldsymbol{E} 9$ [...]Tenho, sinto muitas saudades[...] $\boldsymbol{E} 10$ [...]dias sim, dias não[...] E 11 [...]Sinto... ai ai[...] $\boldsymbol{E} 12$ [...] ]eu sinto, por que meu pai já morreu[...] E 13 [...]Sinto. Saudades demais[...] E 15 [...]Tenho... mas eu não quero ir pra lá[...] E 16 [...]Sim... sinto saudade da minha casa[...]

$\mathrm{Na}$ atual conjuntura social os idosos cada vez mais deixados longe da convivência familiar se interagem entre si buscando meios de sobrevivência com as pessoas que antes não faziam parte de suas vidas, mas que devido às mudanças ao seu redor são obrigados a transformar seus sentimentos em meras lembranças, deixando no passado tudo que era de mais importante para seu eu interior, com isso, passa a ter uma vida diferenciada e percebe que independente de suas vontades precisa aprender a encontrar um meio onde a nova vida e a vida anterior se interajam transformando em coisas boas e agradáveis para vivenciar até o fim de suas vidas. Essa situação está refletida tanto na subcategoria anterior quanto na próxima.

Subcategoria 2: Comodismo pela falta dos familiares

$\boldsymbol{E} 4[\ldots]$ [... nu nao... os amigos não se importam comigo. E 5 [...]Não faz saudade nenhuma. $\boldsymbol{E} \mathbf{1 4}[$ [...] sinto não[...] 


\section{Categoria 5: Convívio institucional e relacionamento interpessoal}

Segundo o autor do parágrafo anterior (Tomasini, 2007), os paradigmas relacionados ao convívio em uma instituição podem ser desmistificados trazendo a possibilidade de conquistas e realizações no mundo diferenciado, resgatando seus anseios familiares.

Diante disso. Pode-se observar a comprovação das palavras de Souza, através das respostas a seguir:

$\boldsymbol{E} 1$ Aqui[ [...] trabalhando, tenho uns conhecidos aqui[...] $\boldsymbol{E} \mathbf{2}$ Eu não posso ir para rua[...] $\boldsymbol{E} 3$ [...]me dou bem com todo mundo[...] $\boldsymbol{E} \mathbf{4}[$ [...]bem cuidado, tem que gostar dos outros idosos[...] $\boldsymbol{E} 5$ [...] tenho muitos amigos aqui[...] $\boldsymbol{E} \mathbf{6}$ É bom [... ]faço nada não[...] $\boldsymbol{E} 7$ É razoável, eu tenho uns colegas aqui[...] $\boldsymbol{E} \boldsymbol{8}$ Tô achando ruim[...] $\boldsymbol{E} \boldsymbol{9}$ Gosto de conviver aqui... me sinto bem[...] $\boldsymbol{E} \mathbf{1 0}$ É bom, não é ruim... me sinto bem [...] $\boldsymbol{E} 11$ [...] gosto de viver aqui, todos são bons comigo. $\boldsymbol{E} 12$ [...] gosto de viver aqui[ [...] $\boldsymbol{E} 13$ [...] convivo bem[...] $\boldsymbol{E} 14$ [...] aqui é um paraíso[...] $\boldsymbol{E} 15$ [...] eu gosto, não tenho amigos mais faço, olha ai vocês que vem me ver[...] $\boldsymbol{E} \mathbf{1 6}$ [...] eu gosto de viver aqui, me sinto bem.

\section{Considerações Finais}

Diante dos dados analisados anteriormente pode-se perceber que a vivência do idoso em uma instituição de longa permanência está intrinsiquicamente relacionado com o modo em que esses idosos ingressaram nesse ambiente, como transcorreu sua vinda e posterior permanência. Lidamos com um País que ao longo dos anos vindouros estarão classificados como um País de idosos, isso de acordo as estatísticas descritas no inicio desse artigo, com isso, pode compreender que falar de idosos no seio familiar ou em instituições torna-se hoje tema de grande relevância social tanto no Brasil quanto em outros países correlacionados na cadeia de crescimento populacional mundial.

Outro fato de igual teor de importância e relevância eticamente falando do significado da vivencia dos idosos em instituições está fortemente entrelaçado com a aceitação do mesmo ao novo espaço social, tento que conviver com pessoas que jamais fizeram parte do seu meio social ou que tenham conhecido em qualquer lugar, isso respinga na ideia de nova adaptação social com rotina diferenciada e totalmente distorcida da convivência em família, por mais que esse idoso receba visitas constantes, torna-se cada vez menos intenso seu convívio com os entes queridos. 
Sendo assim, conclui-se que o idoso institucionalizado é um ser transformado em decorrências das ações sofridas desde o momento do desligamento em família ao momento de adquirir hábitos diferenciados e novos ao mesmo tempo já em ambiente institucional, porém, esse período irá depender apenas da maneira em como ele foi aceito e acolhido por todos que ali habitam. Uma instituição de longa permanência apesar de ser vista de forma negativa por toda população local, trata-se de lugar apenas novo para cada um que chega, nem ruim, nem bom, apenas novo, como qualquer moradia que podemos estar usando naquele momento por necessidade de compra/venda, ou aluguel, assim é o ambiente institucional, apenas outra casa que cada idoso irá conhecer e tentar se adaptar a depender da convivência com cada um.

O cuidar é um exercício constante, baseado nas necessidades do idoso, atender as demandas que vão surgindo no decorrer do processo de institucionalização e que necessitam ser aprendidas no enfrentamento do cotidiano e sendo orientadas por profissionais capacitados como o enfermeiro e o cuidador familiar. $\mathrm{O}$ enfermeiro é fundamental no processo do cuidar e para uma melhor qualidade de vida no envelhecimento institucional.

\section{Referências}

BARDIN, L. Análise de conteúdo. Tradução Luís Antero Reto- Augusto Pinheiro. Lisboa: Edições 70; 2012. Edição revista e ampliada.

BESSA, M.E.P.; SILVA, M.J. Motivações para o ingresso dos idosos em instituições de longa permanência e processos adaptativos: um estudo de caso. Texto Contexto Enferm. Florianópolis, v. 17, n. 2, p. 258-265, jun., 2008.

CARVALHO, J.A.M.; GARCIA, R.A. O envelhecimento da população brasileira: um enfoque demográfico. Cad. Saúde Pública, Rio de Janeiro, 19(3):725-733, mai-jun, 2003.

CARVALHO, M.C. (org.). A família contemporânea em debate. São Paulo: Cortez, 2003.

HALBWACHS, M. A memória coletiva. Tradução de Beatriz Sidou. $2^{\mathrm{a}}$ ed. São Paulo: Centauro, 2013.

MINAYO, M.C.; S. Pesquisa Social: teoria, método e criatividade. Suely Ferreira Deslandes; Romeu Gomes; Maria Cecília de Souza Minayo (organizadora). 29 ed. Petrópolis: Vozes, Rio de Janeiro, 2011, pág. 21.

Ministério da Saúde (Brasil). Guia Prático do Cuidador. Secretaria de Atenção à Saúde. Secretaria de Gestão do Trabalho e da Educação na Saúde. Brasília, 2008; Páginas 05 e 07. 
BRASIL. Ministério da Saúde. Secretaria de Atenção à Saúde. Departamento de Ações Programáticas e Estratégicas. Caderneta de saúde da pessoa idosa: manual de preenchimento / Ministério da Saúde, Secretaria de Atenção à Saúde, Departamento de Ações Programáticas e Estratégicas. - Brasília: Editora do Ministério da Saúde, 2008.

RICHARDSON, R.J. Pesquisa Social: métodos e técnicas. 3. Ed. Ver. E ampl. São Paulo: Atlas, 1999.

RODRIGUES, R.A.P.; MARQUES, S.; FABRÍCIO, S.C.C. Envelhecimento, saúde e doença. Arq. eriatr. Gerontol., v.4, n.1, p.15-20, 2000.

ROSA, M. Psicologia Evolutiva: psicologia da idade adulta. 1993. Petrópolis: Vozes. Miranda, Thaís C. Senescência e senilidade - O que é isso?

ROSA, T.E.C.; BENÍCIO, M.H.D.; LATORRE, M.R.D.O; RAMOS, L.R. Fatores determinantes da capacidade funcional entre idosos. Rev. Saúde Pública, v.37, n.1, p.40-8, 2003.

SOUZA, J.L.C. Asilo para idosos: o lugar da face rejeitada. Jornal da Universidade Federal do Pará, Belém, ano 4, nº 1, p. 77-86, 2003.

TEIXEIRA, M.B. Empoderamento de idosos em grupos direcionados à promoção da Saúde. 2000. Dissertação (Mestrado) - Escola Nacional de Saúde Pública, FIOCRUZ, Rio de Janeiro.

TOMASINI, S.L.V.; ALVES, S. Envelhecimento bem-sucedido e o ambiente das instituições de longa permanência. RBCEH. Passo Fundo, v. 4, n. 1, p. 88-102, jan./jun., 2007.

WORLD Healt Organization (Who). Envelhecimento Ativo: uma política de Saúde. Brasília: Organização Pan-Americana da Saúde, 2005.

\section{Como citar este artigo (Formato ABNT):}

GOMES, Renara Meira; ROCHA, Jessica de O.; SANTOS, Maria da Conceição Q. dos; SALES, Zenilda N.;LINHARES, Eliane F.; BASTOS, Norma L. de M. V. Significado da Vivência em Instituição de Longa Permanência. Id on Line Rev.Mult. Psic., 2018, vol.12, n.40, p.925-938. ISSN: 1981-1179.

Recebido: $25 / 05 / 2018$

Aceito 28/05/2018 